\title{
Consistency and sealing of advanced bipolar tissue sealers
}

This article was published in the following Dove Press journal:

Medical Devices: Evidence and Research

20 April 2015

Number of times this article has been viewed

\section{Edward G Chekan \\ Mark A Davison \\ David W Singleton \\ John Z Mennone \\ Piet Hinoul}

Ethicon, Inc., Cincinnati, OH, USA

Correspondence: Piet Hinoul

Ethicon, Inc., Route 22 West,

PO Box I5I, Somerville, NJ 08876, USA

$\mathrm{Tel}+\mathrm{I} 9082183520$

Email phinoul@its.jnj.com
Objectives: The aim of this study was to evaluate two commonly used advanced bipolar devices (ENSEAL ${ }^{\circledR}$ G2 Tissue Sealers and LigaSure ${ }^{\mathrm{TM}}$ Blunt Tip) for compression uniformity, vessel sealing strength, and consistency in bench-top analyses.

Methods: Compression analysis was performed with a foam pad/sensor apparatus inserted between closed jaws of the instruments. Average pressures (psi) were recorded across the entire inside surface of the jaws, and over the distal one-third of jaws. To test vessel sealing strength, ex vivo pig carotid arteries were sealed and transected and left and right (sealed) halves of vessels were subjected to burst pressure testing. The maximum bursting pressures of each half of vessels were averaged to obtain single data points for analysis. The absence or presence of tissue sticking to device jaws was noted for each transected vessel.

Results: Statistically higher average compression values were found for ENSEAL ${ }^{\circledR}$ instruments (curved jaw and straight jaw) compared to LigaSure ${ }^{\mathrm{TM}}, P<0.05$. Moreover, the ENSEAL ${ }^{\circledR}$ devices retained full compression at the distal end of jaws. Significantly higher and more consistent median burst pressures were noted for ENSEAL ${ }^{\circledR}$ devices relative to LigaSure ${ }^{\mathrm{TM}}$ through 52 firings of each device $(P<0.05)$. LigaSure ${ }^{\mathrm{TM}}$ showed a significant reduction in median burst pressure for the final three firings (cycles 50-52) versus the first three firings (cycles 1-3), $P=0.027$. Tissue sticking was noted for $1.39 \%$ and $13.3 \%$ of vessels transected with ENSEAL ${ }^{\circledR}$ and LigaSure ${ }^{\mathrm{TM}}$, respectively.

Conclusion: In bench-top testing, ENSEAL ${ }^{\circledR}$ G2 sealers produced more uniform compression, stronger and more consistent vessel sealing, and reduced tissue sticking relative to LigaSure ${ }^{\mathrm{TM}}$.

Keywords: ENSEAL, sealing, burst pressure, laparoscopic, compression, LigaSure

\section{Introduction}

Advanced bipolar and ultrasonic energy devices are now routinely utilized for sealing and transecting blood vessels in a number of surgical specialties such as gynecologic, urologic, cardio-thoracic, and colorectal. ${ }^{1-4}$ Advantages provided by modern energy technologies over conventional monopolar electrosurgery include limited risk of thermal injury, elimination of dispersive electrodes, and enhanced sealing capability, especially in blood vessels larger than $1-2 \mathrm{~mm}$ in diameter. ${ }^{5}$ In addition, the need for laparoscopic suture ligation, which is technically demanding and time consuming, has been greatly reduced. Advanced bipolar devices are particularly advantageous for sealing larger vessels up to 5-7 $\mathrm{mm}$ in diameter through uniform compression and efficient energy delivery. ${ }^{5,6}$ Surgical hemostasis with advanced bipolar technology is accomplished with precise delivery of high-frequency/low-voltage electric current that 
is converted to thermal energy, which collapses vessel walls and denatures collagen and elastin, forming a hemostatic seal. ${ }^{7}$ Traditional bipolar devices also employ heat to cause clotting; coaptation and crosslinking of vessel collagen create a seal, followed by thrombus formation that blocks the flow of blood (Figure 1A). However, these earlier devices may exhibit incomplete sealing as a result of inefficient energy delivery secondary to suboptimal compression and more stray current (Figure 1B) relative to modern advanced bipolar instruments. Advanced bipolar devices, on the other hand, are able to create stronger and more uniform compression, and they employ unique ways of controlling the delivery of energy and heat. These features work in combination to provide stronger vessel seals.

Essential parameters necessary for blood vessel electrocoagulation include homogeneously distributed compression, critical temperature, and time, allowing for optimal formation of the coagulum and strong vascular sealing. ${ }^{1,8-10}$ Variations in compression force were shown to have a substantial effect on sealing of carotid arteries in ex vivo analyses. ${ }^{10} \mathrm{~A}$ potential weakness in some advanced bipolar sealing devices is uneven (decreasing) compression from the proximal to the distal tip of the instrument's end effector, which reduces sealing quality and consistency. ${ }^{1}$ Another limitation, most prominent in nonarticulating devices, is the difficulty of approaching target tissue perpendicularly (especially during
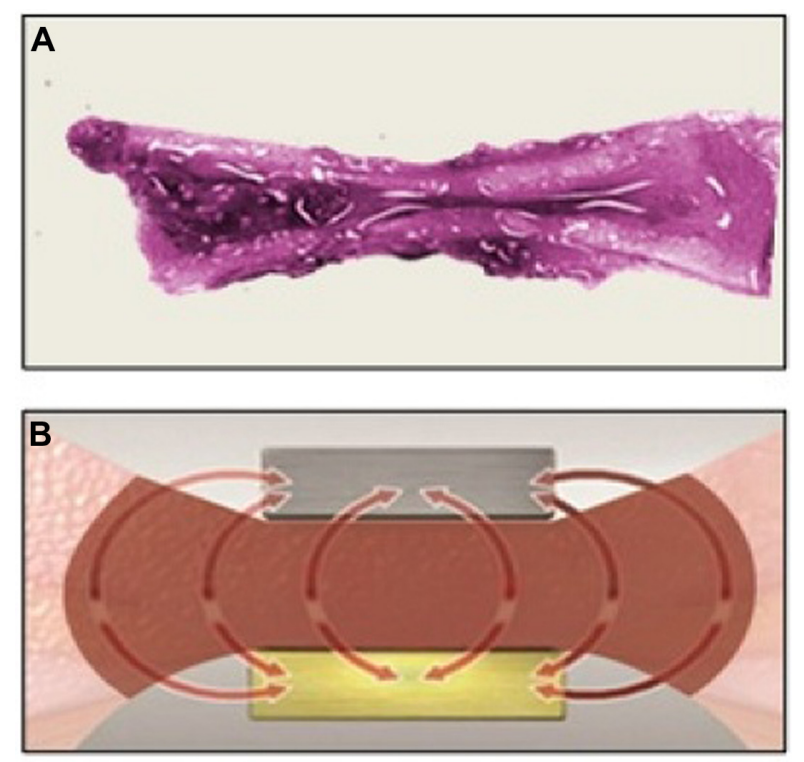

Figure I Vessel sealing with traditional bipolar devices.

Notes: (A) Porcine artery sealed with conventional (nonadvanced) bipolar technology shows an incomplete collapse of the vessel. The seal is formed by coaptation and crosslinking of collagen followed by thrombus formation that blocks the remainder of the lumen. Panel (B) depicts electric current flow from a traditional bipolar device. Thermal energy is mainly focused in tissue held between the jaws, but as tissue desiccates, increasing resistance forces current and heat laterally as shown. laparoscopic procedures). A perpendicular $\left(90^{\circ}\right)$ approach with respect to vessels minimizes the length of the seal and therefore has the potential to affect seal strength. ${ }^{11}$

Advanced bipolar devices should ideally provide uniform tissue compression across the full jaw length to allow for consistent sealing. In complex procedures, a single sealing device may be fired many times, requiring stable performance for adequate hemostasis. These observations highlight the importance of evaluating bipolar devices in terms of their compression parameters and sealing reliability over multiple firings. Therefore, the aim of this report was to characterize the compression uniformity, seal strength, and sealing performance over time for two commonly utilized advanced bipolar devices: the ENSEAL ${ }^{\circledR}$ G2 family of tissue sealers and the LigaSure ${ }^{\mathrm{TM}}$ Blunt Tip laparoscopic instrument.

\section{Materials and methods Study design}

Comparative, bench-top studies were performed to assess compression strength and vessel sealing quality of advanced bipolar instruments over multiple firings. Devices included the ENSEAL ${ }^{\circledR}$ G2 Tissue Sealers (ENSEAL), ENSEAL ${ }^{\circledR}$ G2 Articulating Tissue Sealers (ENSEAL Articulating; Ethicon Endo-Surgery, Cincinnati, OH, USA), and the LigaSure ${ }^{\mathrm{TM}}$ $5 \mathrm{~mm}$ Blunt Tip laparoscopic instrument (LigaSure; LF1537, Covidien, Mansfield, MA, USA).

\section{Compression testing}

Compression forces for the ENSEAL Articulating and LigaSure devices were assessed utilizing a foam pad and sensor (Tekscan 5027) placed between closed jaws of the instruments. Closed-jaw pressures (psi) were recorded with I-Scan ${ }^{\circledR}$ software (Tekscan ${ }^{\circledR}$ Inc., Boston, MA, USA). For each measurement, the average pressure over the tissue contact surface of the jaws was calculated as the mean of all data points above 24 psi. Values less than 24 psi were considered equivalent to background. For ENSEAL, full jaw pressure is exerted when the I-BLADE ${ }^{\circledR}$ is completely deployed, which closes and holds the jaws to a set gap. Because deployment of the I-BLADE ${ }^{\circledR}$ would destroy the foam pad/sensor, a closejaw fixture was used to hold the jaws at this same set gap, thus replicating the applied pressure. The close-jaw fixture consisted of a c-clamp configured to engage the flat cam surfaces of both the upper and lower jaws normally engaged by the I-BLADE ${ }^{\circledR}$. Closing the c-clamp brought these cam surfaces together, which is how the I-BLADE ${ }^{\circledR}$ closes the jaws. With the pad/sensor placed in the device jaws, a micrometer mounted to the c-clamp was used to measure the closure 
distance to ensure the fixture produced exactly the same gap as the (normally) deployed I-BLADE ${ }^{\circledR}$. Specific devices tested in the analysis were five ENSEAL Articulating straight jaw, six ENSEAL Articulating curved jaw, and five LigaSure. Each individual instrument was tested six times, to provide a sample size of $n \geq 30$. For analysis of the total jaw, all data points along the entire surface in contact with the sensor were averaged; whereas for the distal tip, only data from the distal third of the jaw were counted. Testing for normality was performed using the Anderson-Darling method; and where normal data distributions were found, two-sample $t$-tests were employed to compare means for the determination of statistical significance. Most data sets exhibited normal distributions except for the distal tip data for ENSEAL straight jaw and LigaSure. Therefore, a comparison of medians was the most appropriate statistic for distal tip analyses and the Mann-Whitney test was utilized. For all comparisons, $P$-values less than 0.05 were considered significant.

\section{Vessel sealing and burst pressure}

Fresh Porcine carotid arteries were obtained from Animal Biotech Industries (Danboro, PA, USA). Vessels were examined for leak integrity, measured, and sorted according to outer diameter sizes of $5 \mathrm{~mm}(4.5-5.4 \mathrm{~mm}), 6 \mathrm{~mm}$ $(5.5-6.4 \mathrm{~mm})$, and $7 \mathrm{~mm}(6.5-7.5 \mathrm{~mm})$. Carotid arteries were sealed and transected with ENSEAL and LigaSure devices. Each device was operated according to the accompanying instructions for use. ${ }^{12,13}$ In general, each tissue specimen was clamped in the device end effector, energy was applied until the generator signaled cycle completion, and the tissue was transected and released from the end effector. Sticking of vessel tissue to the instruments' end effector was determined as follows: If noticeable residue remained on the device following transection, which was not easily removed (ie, was not released by simple manipulation of the device), the vessel was documented as sticking. The number of sticking events was expressed as a proportion (percentage) of the total transections for each device, and the difference in proportions test was employed to examine for statistical differences in the occurrence of sticking between device types.

To evaluate sealing strength over multiple firings, each individual instrument was fired through 52 activations (cycles). The protocol for each device consisted of three consecutive vessel transections followed by four sequential activations on porcine connective and fatty tissues (to simulate multiuse of the instrument). This pattern was performed seven times, followed by three final vessel transections for a total of 52 firings per instrument and 24 sealed/transected vessels.
Three samples of each device type, (3) ENSEAL curved jaw, (3) ENSEAL straight jaw, and (3) LigaSure, were tested with this protocol.

The left and right halves of sealed vessels were subjected to testing with a burst pressure system consisting of a computer-controlled syringe pump (Harvard Apparatus, Holliston, MA, USA) with an inline pressure transducer. Physiologic saline was infused into the transected vessel halves at $47 \mathrm{~mL} /$ minute, and intraluminal pressure data were recorded until maximum burst pressure was reached at seal failure. The maximum bursting pressures of each half of vessels were averaged to obtain single data points for analyses. To determine statistical significance between burst pressure data sets, nonparametric Kruskal-Wallis comparisons of medians were performed.

\section{Results}

Compression strength and uniformity were evaluated for ENSEAL Articulating and LigaSure; pressure profiles across the entire jaw length are shown in Figure 2. Whole-jaw and distal one-third (tip) compression values were calculated for ENSEAL Articulating devices compared to LigaSure (Table 1). The compression values for the distal tip as compared to the whole-jaw compression may be expressed as a ratio (percentage), which illustrates compression consistency from distal to proximal ends for each device jaws, as shown in Table 1. Mean whole-jaw and median distal tip compression for ENSEAL Articulating (both straight and curved jaw) were significantly higher than those for LigaSure, $P<0.05$.

The sealing consistency over multiple firings was examined in 5-mm-diameter porcine carotid arteries transected with ENSEAL and LigaSure devices, fired through 52 activations (cycles). Figure 3A shows burst pressures averaged at eight intervals, where each interval contains the average of three consecutive firings (ie, interval $1=$ cycles $1-3$, interval $2=$ cycles $8-10, \ldots$, interval $8=$ cycles $50-52)$. The LigaSure device showed a reduction in burst pressures over multiple firings, including a $40 \%$ decrease in the mean value at the last interval relative to the first (Figure 3B). Table 2 includes the median burst pressures calculated for all samples of each device at the first and last intervals (three of each device type were tested). The ENSEAL instruments maintained full sealing strength through 52 firings; no significant differences were noted between initial and last intervals. LigaSure exhibited a significant decrease of $727 \mathrm{mmHg}$ at the last interval versus the first, $P=0.027$. Figure 4 depicts the overall burst pressure data (including all firings) for each device, represented as box plots. ENSEAL straight and 
$\longleftarrow$ Distal $\quad$ Proximal $\longrightarrow$

A

ENSEAL straight jaw pressure profile

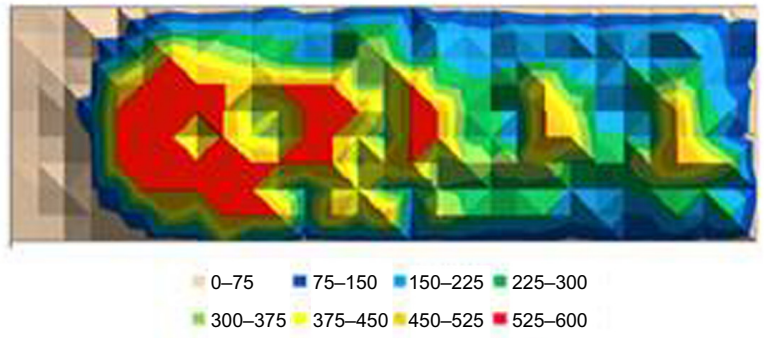

B

ENSEAL curved jaw pressure profile

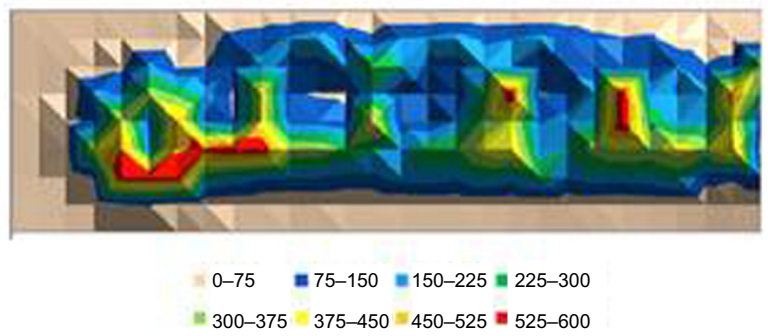

C

LigaSure pressure profile

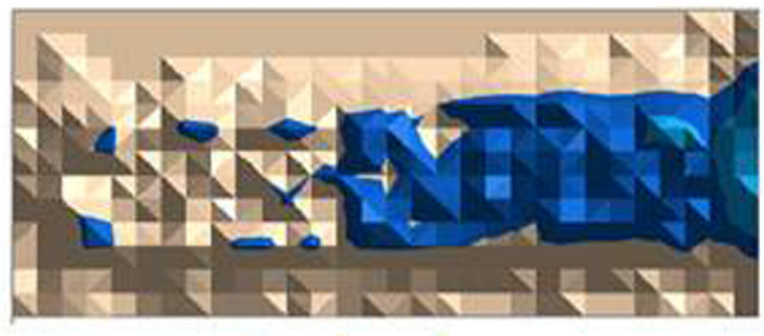

$0-75=75-150=150-225$

Figure 2 Compression profiles for ENSEAL Articulating (A, B) and LigaSure (C) devices.

Notes: Colors indicate pressure ranges (psi) across the full length of devices' closed jaws. Orientation of proximal and distal ends of jaws is designated as shown.

curved jaw showed significantly higher overall median burst pressures relative to LigaSure.

Tissue sticking was evaluated following transections of equal numbers of 5- to 7-mm-diameter porcine carotid arteries. Sticking events were noted for $1.39 \%$ of vessels transected with ENSEAL (straight and curved jaw combined), whereas LigaSure showed sticking in $13.3 \%$ of transections. The two proportions test yielded a statistical difference $(P=0.007 ; 95 \%$ confidence interval $0.03259,0.20660)$ comparing LigaSure with ENSEAL (straight and curved jaw combined). Sticking for ENSEAL straight jaw versus curved jaw (1.1\% and 1.7\%, respectively), did not differ significantly.

\section{Discussion}

A major objective of the current study was to determine if the advanced bipolar devices being tested would maintain
Table I Average and median compression values

\begin{tabular}{llll}
\hline Device & $\begin{array}{l}\text { Full jaw } \\
\text { compression, } \\
\text { mean psi (SD) }\end{array}$ & $\begin{array}{l}\text { Distal tip } \\
\text { compression, } \\
\text { median psi }\end{array}$ & $\begin{array}{l}\text { Distal }^{\mathrm{a}} \\
\text { third/full } \\
\text { jaw (\%) }\end{array}$ \\
\hline LigaSure & $80.75(2.7)$ & 57.1 & 73 \\
& $\mathrm{n}=30$ & $\mathrm{n}=30$ & \\
ENSEAL Articulating & $253.9^{*}(30.1)$ & $306.2^{*}$ & $\mathrm{II} 5$ \\
(straight jaw) & $\mathrm{n}=30$ & $\mathrm{n}=30$ & 100 \\
ENSEAL Articulating & $196.8^{*}(23.5)$ & $197.7^{*}$ & $\mathrm{n}=36$ \\
(curved jaw) & $\mathrm{n}=36$ & $\mathrm{n}$ & \\
\hline
\end{tabular}

Notes: aMean of individual compression ratios (distal tip/full jaw) for each device tested (\%); $* P<0.05$ relative to LigaSure.

Abbreviation: SD, standard deviation.

uniform compression strength across the entire length of the instruments' jaws. Statistically higher average whole-jaw and median distal (one-third) tip compression values were noted for ENSEAL Articulating (straight and curved jaw) devices compared to LigaSure. Moreover, the distal tip of the ENSEAL instruments maintained $100 \%$ or greater of their full jaw compression force, indicating consistent and fully distributed pressure. Reyes et al determined that variations in apposition force (compression) had a major effect on sealing strength of ex vivo sheep carotid arteries. ${ }^{10}$ In that analysis, it was found that vessels were optimally sealed with pressures of 2.4-3.8 $\mathrm{MPa}$ (which equates to $348-551 \mathrm{psi}$ ), at $90^{\circ} \mathrm{C}$ and a clamp time of 10 seconds. Taken together, published results and data described here highlight the importance of uniform compression along the entire length of the jaw for producing strong vessel seals and adequate surgical hemostasis.

Complex procedures such as colorectal surgery may require more than one hundred activations of an energy device, including transection and/or sealing of multiple isolated blood vessels. ${ }^{14}$ Therefore, consistency of the sealing and cutting mechanism in advanced bipolar instruments is critical for adequate hemostasis. For evaluating sealing performance over many firings, ex vivo burst pressure testing is a convenient method and this technique is widely utilized to test the integrity of blood vessel seals produced either in vivo or ex vivo. ${ }^{15-17}$ In the current burst pressure analyses, ENSEAL tissue sealers maintained consistent seal strength through 52 firings of the device, whereas seals performed with LigaSure showed a reduction in burst pressure over multiple firings.

Tissue sticking is known to be a significant concern in electrosurgery. ${ }^{18,19}$ When heated tissue adheres to the sealing device's hot surfaces, electrical resistance is increased, which inhibits energy delivery to targeted tissue making the process less effective and more time consuming. In addition, sticking tissue may lead to disruption or destruction of the seal as well as adjacent tissue, thereby causing bleeding 
A
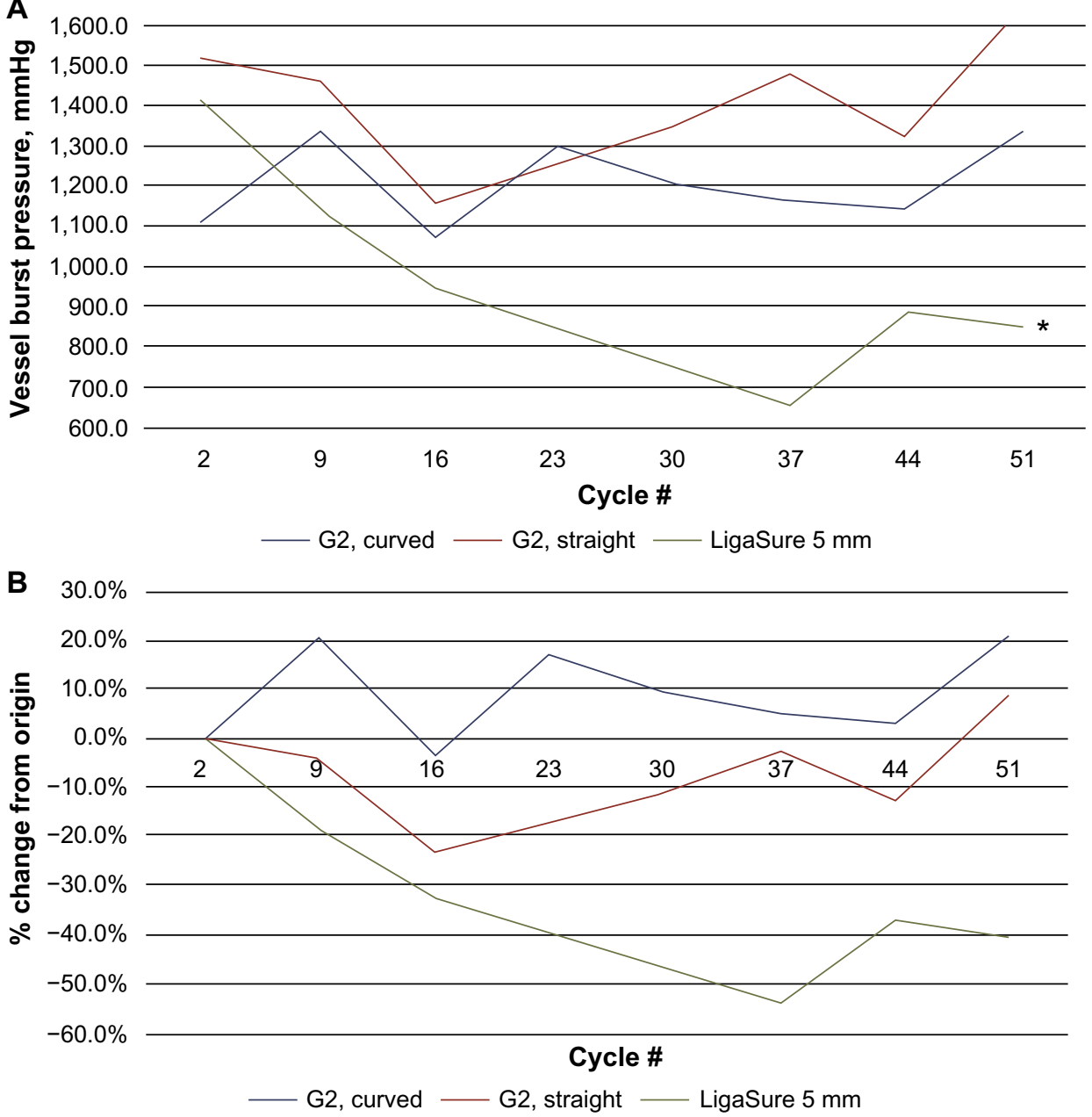

Figure 3 Vessel burst pressures through multiple firing cycles of sealing devices.

Notes: (A) Ex vivo porcine carotid artery mean burst pressures were plotted at eight intervals (cycle numbers as indicated) for vessels sealed with LigaSure or ENSEAL G2 (straight and curved jaw). *Significant decrease in burst pressures for LigaSure at last interval (cycles 50-52) compared to the first interval (cycles $\mathrm{I}-3$ ), $P=0.027$ comparing interval medians. (B) Percent change in mean burst pressures through 52 firing cycles (eight intervals). Origin = first interval.

and the need for additional sealing or touch ups. The model used in this study does not account for the effect of blood coagulum in vivo, which undoubtedly contributes to sticking in an operative setting. Therefore, it is uncertain as to whether the sticking results presented here could be applied to an in vivo operative context. Nonetheless, the ex vivo

Table 2 Median burst pressure change over multiple firings: Interval I (cycles I-3) and 8 (cycles 50-52); change = interval 8 minus interval I

\begin{tabular}{llll}
\hline Device & $\begin{array}{l}\text { Interval I } \\
\text { median } \mathbf{m m H g}\end{array}$ & $\begin{array}{l}\text { Interval 8 } \\
\text { median } \mathbf{~ m m H g}\end{array}$ & $\begin{array}{l}\text { Change (8-I) } \\
\mathbf{m m H g}\end{array}$ \\
\hline LigaSure & $\mathrm{I}, 424 . \mathrm{I}$ & $696.5^{*}$ & -727.6 \\
& $\mathrm{n}=8$ & $\mathrm{n}=8$ & \\
ENSEAL & $\mathrm{I}, 499$ & $\mathrm{I}, 5 \mathrm{I} 5$ & $\mathrm{1}$ \\
straight & $\mathrm{n}=9$ & $\mathrm{n}=8$ & \\
ENSEAL & 998.2 & $\mathrm{I}, 230.1$ & 231.9 \\
curved & $\mathrm{n}=9$ & $\mathrm{n}=9$ & \\
\hline
\end{tabular}

Note: *Significant decrease $(P=0.027)$ relative to LigaSure at interval I. vessels in this experiment clearly showed less sticking to ENSEAL devices relative to LigaSure. This reduced sticking may contribute to the consistent sealing performance found over multiple firings with ENSEAL. The ENSEAL instruments contain an offset electrode configuration and positive temperature coefficient nanoparticles in the jaw (Figure 5A). This configuration minimizes thermal spread and sticking, while allowing complete hemostatic seals (Figure 5B). When the temperature in the jaw and tissue rises to approximately $100^{\circ} \mathrm{C}$, the positive temperature coefficient polymer expands and the conductive chains break apart, thus interrupting the flow of electrical current and preventing further increases in temperature.

Although the scope of the current report was limited to key elements required for vascular sealing and hemostasis, published preclinical and clinical data have established the effectiveness of advanced bipolar sealing in vivo and are consistent with results presented here. Overhaus et al com- 


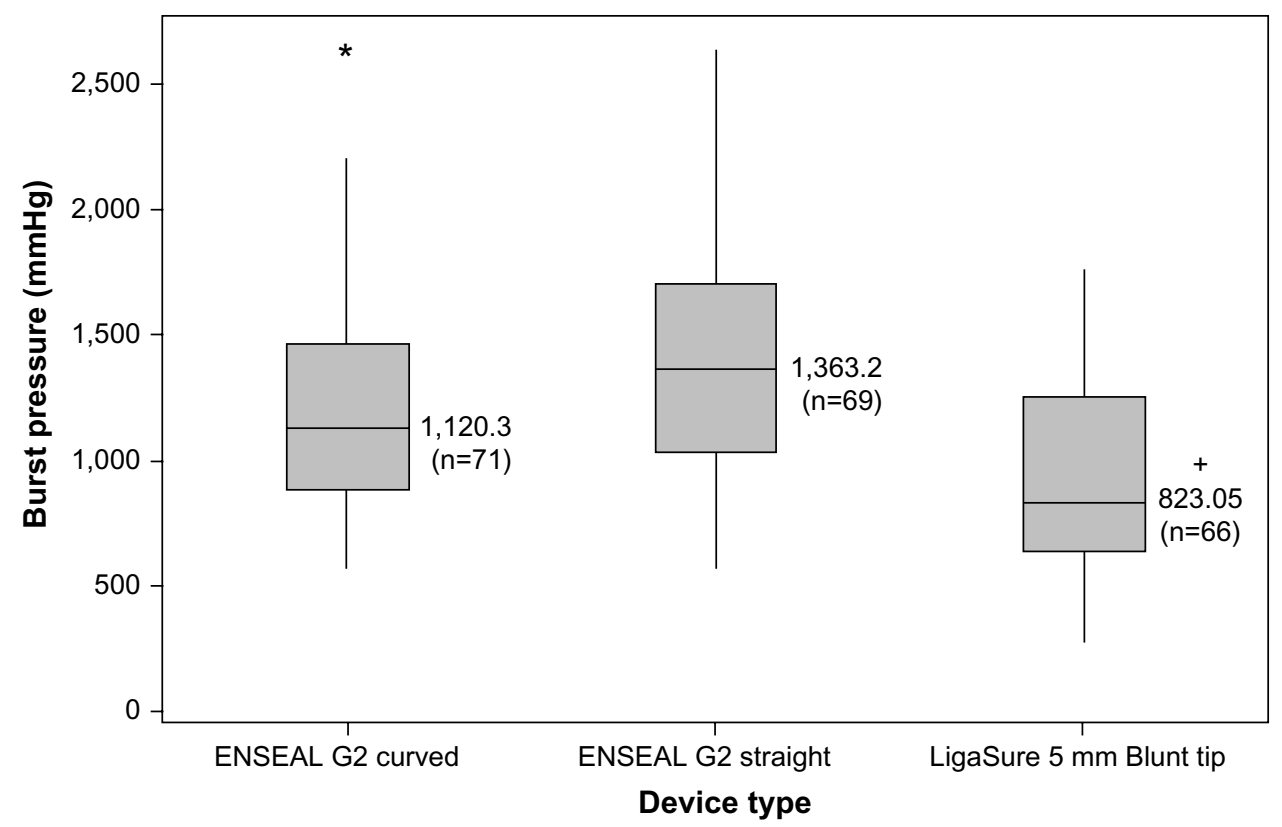

Figure 4 Ex vivo burst pressures for porcine carotid arteries transected with ENSEAL G2 and LigaSure.

Notes: Median values $(\mathrm{mmHg})$ and total number of vessels included $(\mathrm{n})$, are shown. ${ }^{+} \mathrm{P}<0.05$ comparing LigaSure with both ENSEAL devices; ${ }^{*}$ outlier data point.

pared ENSEAL with conventional clamp and ligation for resection of bowel, colon, and kidney in a porcine model. ${ }^{20}$ Blood loss and operation time were significantly lower for the ENSEAL surgeries, and lateral thermal spread was $1 \mathrm{~mm}$ or less. Bibi et al found that human mesenteric arteries sealed with ENSEAL during laparoscopic colorectal surgery
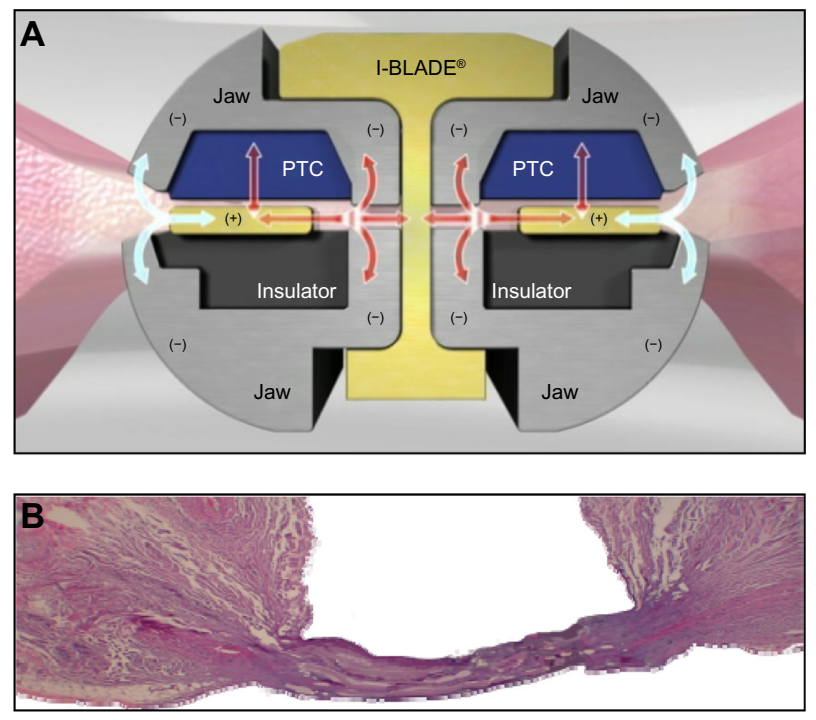

Figure 5 ENSEAL jaw structure and vessel sealing.

Notes: (A) Jaws and I-BLADE ${ }^{\circledR}$ are illustrated in cross-section. Positive temperature coefficient material (PTC), energy transfer (arrows), and offset electrode configuration with active $(+)$ and return $(-)$ electrodes, which confine current flow between the device jaws. (B) Hematoxylin and eosin-stained image of a sealed porcine carotid artery: The ability to maximize the use of compression in combination with optimal heat transfer leads to collapse of the vessel wall, loss of the lumen, and eventually a complete collagen seal. exhibited mean (ex vivo) burst pressures of $\geq 853 \mathrm{mmHg}$ and lateral thermal damage $<1 \mathrm{~mm} .{ }^{3}$ Other clinical studies using ENSEAL during laparoscopic liver resections and hysterectomies each found equal or better outcomes in terms of effective sealing and estimated blood loss relative to comparative methods. ${ }^{21,22}$

Limitations of this analysis are mainly related to the ex vivo approach for assessing vessel seal quality (ie, burst pressures). The technique does not account for the effects of in vivo parameters such as tissue healing, chronic tensile strength and delayed fusion failures, compression ischemia, and pulsatile blood flow subjecting vessels to physiologic shear forces. ${ }^{10}$ However, the reproducibility and supraphysiologic burst pressures achieved with this approach provide a reliable index of the safety and consistency that devices will deliver in vivo. Other limitations include relatively small sample size and restriction to 5-mm-diameter vessels in the burst pressure analysis. Finally, it must be noted that this work was funded and performed by the manufacturer of the ENSEAL tissue sealing technology and all authors are employees of Ethicon, Inc. However, risk of bias was minimized by using a standardized preclinical model for all devices in the respective studies.

\section{Conclusion}

These bench-top analyses have demonstrated superior sealing characteristics in porcine carotid arteries transected by the ENSEAL ${ }^{\circledR}-\mathrm{G} 2$ devices. ENSEAL outperformed LigaSure 
with regard to uniformity of jaw compression, reduced tissue sticking, and increased burst pressures in sealed/transected vessels.

\section{Acknowledgments}

The authors wish to thank the personnel who participated in acquiring the data presented in this report: B Dickerson, K Huey, S Killinger, F Lewis, J Mallow, E Niehaus, A Pierce, R Rowe, B Schaefer, S Sell, D Shaw, and A Voegele.

\section{Disclosure}

This work was funded and performed by the manufacturer of the ENSEAL tissue sealing technology (Ethicon, Inc.). The authors report no other conflicts of interest in this work.

\section{References}

1. Eick S, Loudermilk B, Walberg E, Wente MN. Rationale, bench testing and in vivo evaluation of a novel $5 \mathrm{~mm}$ laparoscopic vessel sealing device with homogeneous pressure distribution in long instrument jaws. Ann Surg Innov Res. 2013;7:1.

2. Seehofer D, Mogl M, Boas-Knoop S, et al. Safety and efficacy of new integrated bipolar and ultrasonic scissors compared to conventional laparoscopic 5-mm sealing and cutting instruments. Surg Endosc. 2012; 26(9):2541-2549.

3. Bibi S, Coralic J, Velchuru V, et al. A prospective study of in vivo and ex vivo sealing of the human inferior mesenteric artery using an electrothermal bipolar vessel-sealing device. J Laparoendosc Adv Surg Tech A. 2014;24(7):471-474.

4. O'Keeffe K, Fuchs K. Laparoscopic-assisted vaginal hysterectomy with bipolar coagulation cutting forceps (ENSEAL(r) trio device) versus suture technique vaginally: A comparative analysis. J Gynecol Surg. 2013;29(3):131-134.

5. Lyons SD, Law KSK. Laparoscopic vessel sealing technologies. J Minim Invasive Gynecol. 2013;20(3):301-307.

6. Kondrup JD, Anderson F, Quick B. Use of the ENSEAL(R) G2 tissue sealer in gynecologic surgery. Surg Technol Int. 2013;23:191-195.

7. Kennedy JS, Stranahan PL, Taylor KD, Chandler JG. High-burststrength, feedback-controlled bipolar vessel sealing. Surg Endosc. 1998; 12(6):876-878.

8. Sigel B, Dunn MR. The mechanism of blood vessel closure by high frequency electrocoagulation. Surg Gynecol Obstet. 1965;121(4): 823-831.

9. Wallwiener CW, Rajab TK, Zubke W, et al. Thermal conduction, compression, and electrical current-an evaluation of major parameters of electrosurgical vessel sealing in a porcine in vitro model. J Minim Invasive Gynecol. 2008;15(5):605-610.
10. Reyes DAG, Brown SI, Cochrane L, Motta LS, Cuschieri A. Thermal fusion: effects and interactions of temperature, compression, and duration variables. Surg Endosc. 2012;26(12):3626-3633.

11. Voegele AC, Korvick DL, Gutierrez M, Clymer JW, Amaral JF. Perpendicular blood vessel seals are stronger than those made at an angle. J Laparoendosc Adv Surg Tech A. 2013;23(8):669-672.

12. Package insert for ENSEAL ${ }^{\circledR}$ G2 Tissue Sealer, Cincinnati OH, USA: Ethicon Endo-Surgery, Inc.; 2011.

13. Package insert for LigaSure ${ }^{\mathrm{TM}}$ Blunt Tip Laparoscopic Sealer/Divider, Mansfield, MA, USA: Covidien, LLC; 2011.

14. Parker G, Tsai B, Dipe N, et al. Clinical utility of a new articulating tissue sealer in laparoscopic colorectal surgery. World J Colorectal Surg. 2014;4:14. Abstract presented at the XXVI Biennial Congress of the International Society of University Colon and Rectal Surgeons, Cape Town, South Africa, September 4-7 2014. Available from: http://services. bepress.com/cgi/viewcontent.cgi?article $=1167 \&$ context=wjcs.

15. Krane C, Pinnell M, Gardner C, Thompson M, Coleman J, Wilkens R. Mechanical test methods for assessing porcine carotid and uterine artery burst pressure following ex vivo ultrasonic ligature seal and transection. J Test Eval. 2011;39:4.

16. Carbonell AM, Joels CS, Kercher KW, Matthews BD, Sing RF, Heniford BT. A comparison of laparoscopic bipolar vessel sealing devices in the hemostasis of small-, medium-, and large-sized arteries. J Laparoendosc Adv Surg Tech A. 2003;13(6):377-380.

17. Novitsky YW, Rosen MJ, Harrell AG, Sing RF, Kercher KW, Heniford BT. Evaluation of the efficacy of the electrosurgical bipolar vessel sealer (LigaSure) devices in sealing lymphatic vessels. Surg Innov. 2005;12(2):155-160.

18. Ou KL, Chu JS, Hosseinkhani H, Chiou JF, Yu CH. Biomedical nanostructured coating for minimally invasive surgery devices applications: characterization, cell cytotoxicity evaluation and an animal study in rat. Surg Endosc. 2014;28(7):2174-2188.

19. Brill AI. Bipolar electrosurgery: convention and innovation. Clin Obstet Gynecol. 2008;51(1):153-158.

20. Overhaus M, Schaefer N, Walgenbach K, Hirner A, Szyrach MN, Tolba RH. Efficiency and safety of bipolar vessel and tissue sealing in visceral surgery. Minim Invasive Ther Allied Technol. 2012;21(6): 396-401.

21. Rothmund R, Kraemer B, Brucker S, et al. Laparoscopic supracervical hysterectomy using ENSEAL vs standard bipolar coagulation technique: randomized controlled trial. J Minim Invasive Gynecol. 2013;20(5): 661-666.

22. Mbah NA, Brown RE, Bower MR, Scoggins CR, McMasters KM, Martin RCG. Differences between bipolar compression and ultrasonic devices for parenchymal transection during laparoscopic liver resection. HPB (Oxford). 2012;14(2):126-131.
Medical Devices: Evidence and Research

\section{Publish your work in this journal}

Medical Devices: Evidence and Research is an international, peerreviewed, open access journal that focuses on the evidence, technology, research, and expert opinion supporting the use and application of medical devices in the diagnosis, treatment and management of clinical conditions and physiological processes. The identification of novel

\section{Dovepress}

devices and optimal use of existing devices which will lead to improved clinical outcomes and more effective patient management and safety is a key feature. The manuscript management system is completely online and includes a quick and fair peer-review system. Visit http://www. dovepress.com/testimonials.php to read real quotes from authors. 